\title{
Individuals as problems: psychology between individuation and the 'illusion of subjectivity'1
}

\author{
Patricio Rojas \\ Goldsmiths, University of London \\ p.rojas@gold.ac.uk
}

Psychology has a problem, a problem with science studies. A problem that -taken slowly- acts as a fruitful, creative challenge, and -taken too quickly- threatens with operating as an abstract and apparently general solution to a discipline that is actually composed by a multi-textured and heterogeneous set of practices, fields and problems. Psychology has a problem with the encounter between science studies, individuals and psychology.

This paper presents, thus, an experimentation with some of the assumptions and possibilities of psychology, but it is specially an invitation to embark on that experimentation knowing full well the many challenges that science studies' informed research have posed to psychology's usual assumptions of what the psychic, subjectivity, agency and even 'the subject' are.

My main proposal here is not completely new, and shares the spirit of a series of heterogeneous works that make a call for a 'foundationless', 'process-oriented' psychology (Brown, 2001; Brown, 2010; Brown \& Stenner, 2009; Nichterlein \& Morss, 2016). These diverse efforts have demanded for a new task for psychology: to develop a new approach, one that analyses individuals as problems amid the folding and unfolding of the vitality of experience. This new route -cartography, perhaps- for psychology would require to "unravel the specific pattern of processes that have connected previously unrelated sets of heterogeneous relations into perceivable forms of individuation" (Tucker, 2012, p. 781). This suggestion is, of course, incompatible with what common sense -and I would also add, most of psychologically-informed research- thinks that defines psychology, its aims and scopes: a human centred study of the intrinsic properties and nature of an often stable, static, single-bounded psychological life owned by an individual.

Surely, most of the people attending this session is directly or indirectly aware of the strong criticism faced by psychology, the notion of subjectivity, and also by the specific and often disembodied "subject" this discipline's practices have, paradoxically, created to -somehow and mysteriouslyembody the closed and single bounded mind, personal psychic realm, or individual subjective space that form its object of study. This individual or psychological subject is often dismissed by STS informed research because its naïve grounding on a supposedly Cartesian sharp distinction between an abstract mind and a buzzing, confusing res extensa or world-stuff. To be fair, psychology's single bounded, enclosed, sovereign subject, master of its own mind, has may have more debts to John Locke's philosophy of consciousness, grounded "in an identity that persists across time", installing thought "within an 'anthropological doublet' between 'being' and 'having', between the 'self' and the 'own'" (Balibar, 2006; Rekret, 2016, p. 232). This is one of the many sources of the idea of identity as an act of self-appropriation, and exercise of self-ownership, a capacity for 'privateness', that both feeds some of the certainties of the strong, liberal subject of psychology and, at the same time, contributes to the displacement of Descartes' res extensa into a res nullius.

\footnotetext{
${ }^{1}$ Paper presented at the joint 4S/EASST conference, Barcelona, September, 2016.
} 
How does this relate to STS and its critique or, maybe more precisely, its rather scarce interest for engaging 'the psychological' or human experience? How did the psychological and human experience become a category of dubious analytic pertinence, of a dead-end that keeps us attached to binary distinctions to overcome such as subject-object, internal-external, individual-collective, human and non-human?

In a myriad of ways, empirical and theoretical, STS have emphasised an approach to things/objects through their meticulous description as fragile achievements amidst local, grounded and complex modes of connectedness and separation. These delicate realisations have a better chance of being rigorously approached through an engagement with practices rather than efforts of correct and general representation. It is this mode of engaging practices that leads to an unavoidable encounter with the fact that no "object" is something to be found in a vacuum or bounded "inside" a body, human or not, but rather an assemblage or arrangement of contingent and fragile configurations where a series of actors -human and non-human- make objects emerge in the midst of a complex socio-material skein that does not respect simplistic distinctions such as object/subject, human/nonhuman, or nature/culture (Law, 2008; Law \& Mol, 1995; Mol, 2010). In other words, as it has been exemplary stated: science studies have reminded psychology and its notion of the individual something sts scholars might consider obvious: that nothing comes without its world (Puig de la Bellacasa, 2012).

Perhaps it is this emphasis, a prominence that is at the same time empirical, theoretical and even ethical, that turns an "object" such as the psychological, and a subject like the continuous, autonomous, foundational individual of a large portion of psychology's work into a problem. Should we cultivate it or dismiss psychology and its ineffable "interiority" of human experience as an old fashioned, naïve, even useless concern for STS informed scholarship?

But there is one particular proposal that has some of the most interesting consequences for psychology and for thinking the psychological and individuals as problems. A specific doctrine, that -1 think- shines the most amongst the bulk of provocative findings and intellectual tools that science studies have crafted to cleverly deal with the techno-scientific world (and beyond) that they make matter. I refer to what a certain reading of what in Whitehead's (1995) attempt to develop a natural philosophy has been come to be known as the 'bifurcation of nature'.

One of the most usual ways in which Whitehead's argument has been translated into STS sensibilities can be found in the work of Bruno Latour (2004a, 2004b), who exposes the futility of the artifice of separating nature between a register of primary qualities -or things in themselves- and secondary qualities -i.e. how said things are "experimented by a consciousness" (Latour, p. 47). This entails a specific call to go beyond the dualism of a natural reality and a subjective realm of personal beliefs, culture and politics that would somehow be projected on it, recoating it. Humanizing it.

One of the pernicious consequences of sustaining the bifurcation of nature would be, precisely, to end up trapped in a form of critique and scholarship that denounces science as an enterprise animated by dark human interests, leaving aside the specificities through which the sciences operate with their objects, and their objects operate on them. Likewise, this would involve the opposite operation of rescuing the human affairs that underlie science as determining it, turning it into another game of deconstruction of power relations, while leaving unattended and unquestioned the specific practices, constraints, and ways in which a world beyond the human makes itself part of techno-science and beyond, participating, resisting, recreating, rejecting, and, in sum, hybridizing human and non-human forms of agency and becoming together (Connolly, 2011). 
This reading of the bifurcation of nature has had laudable effects. In Latour's work, for instance, to avoid the exclusion of the non-human, avoiding to reduce our political and scientific discussions to "humans, their interests, their subjectivities, and their rights" (2004a, p. 69). However, it has allowed us to witness, at the same time, a wider movement in science studies: a disavowal of the psychological, human experience and the individual as something to cultivate as a problem.

A paradigmatic example of the psychological and the individual's fate at the hands of STS' constructivist critique can be found in healthcare and biomedicine related research. On the one hand, avoiding the bifurcation of nature has allowed authors like Jeanette Pols $(2005,2014)$ to creatively reexamine the problem of patient's perspectives and knowledge, far away from their connotations inherited from psychologically-inspired models- as intangible properties contained inside an individual more or less able to -usually verbally- express them to other always human and equally singlebounded individuals.

Through her study of psychiatric hospitals, residential homes and patients with obstructive pulmonary disease, Pols has skilfully described how working with the idea of a patient's "perspective" entails a series of assumptions: that the patient has/owns a perspective, that this is individual, that it is grounded inside the person, that it is eminently cognitive and susceptible of being expressed through verbal or written language, and so on. All of these assumptions, Pols claims, collapse or ignore a large population of healthcare users that do not fit within this cognitive-psychological notion of having a perspective: those whose health, body and consciousness are compromised, when healthcare users cannot talk, write, take an "informed" decision, express a reflexive and clear position in relation to their situation and treatment, and so on.

Pols counter proposal is to nurture the idea that these users do have "perspectives", but they have been researched and conceptualised in an erroneous way. We should shift our attention to what patients do, rather than say, subtlety enacting their perspectives through different forms of agency. For instance, they can do it collectively, or by the way they use healthcare facilities and spaces, or through their often silent preferences when they make themselves part of diagnostic and treatment assemblages. Nothing of this makes us to require a conscious reflection, or to rely in an "interior" subjective-psychological dimension. In her words, "feelings and events only available to those who suffer them", conforming and unmediated, non-contestable knowledge that should be left aside, focusing in the descriptions of knowledge in action instead. This is what authors such as Duff (2014, p. $x)$ have called the 'illusion of subjectivity': the awareness of its mediated and evanescent character.

Efforts such as the aforementioned operate with a notion of experience is loaded with the idea of the individual, enclosed, conscious, ungraspable, etc. But what if we rely on STS critique as a way to turn (human) experience, the psychological and the individual into a problem?

I don't have or seek a definitive answer to this questions, but leaving it open may help whoever is interested in this matter to experiment with some proposals that could lead to a very different notion of experience, psychic life and individuality, one enriched by science studies' challenges and nurtured, at the same time, by often overlooked contributions of the area of psychology.

I cannot help to think, for instance, in the work of one of psychology's so called founding fathers, a prolific and imaginative thinker whose legacy has also left a mark in some of science studies trajectories and reflection. I refer to William James and his work, where experience acts as both the metaphysic stuff of what this dynamic world of movement and change is made of -the idea of a world of pure experience-, and secondly, as some kind of ongoing wave that individuals feel as their own. Here, the individual is rather an effect of the psychological as a field in movement, a wave where 
certain objects present themselves before thought and feeling, luring it towards different forms of affectation (James, 1950). In James' view, mental fields thrive or fade away one after the other, generating different fields of experience which get entangled with objects coming in and out of them as we live, generating a variety of impacts, affects and compositions. The most important, the American author stresses, is that these fields have an ever-changing and indeterminate margin, in a way that subjectivity and the individual -far from being a centre, a limit between the inner and outer world, or acting as a strong foundation of any kind- become a "mass of powers, residual impulses and knowledges" that continuously stretch going beyond any possible stabilisation (James, 1987, p. 442). "As life continues", says James, "there is a constant change in our interest, a constant change of place in our systems of ideas, from the central to the peripheral and from the peripheral to the central parts of consciousness" where we live "the effective world of the individual, the composed world, [of] physical facts, emotional values, in indistinguishable combination" (James, p. 141).

This ways, individuals remain a problem, and the psychological become a field of intersection between continuous and pluralistic forms of life and human and, of course, worldly experience: that conglomerate of "hard elements", of materials such as waves, wind and architectures that "democratize" human beings placing them in a more humble place in relation to the superabundance of reality (James, 2009, p. 131). In other words and following this time another author that can be considered both a founding father of psychology and an inspiration for STS scholarship -(Dewey, 1998, p. 4a)- " it is not experience which is experienced but nature -stones, plants, animals, diseases, health, temperature, electricity, and so on. Things interacting in certain ways are experience; they are what is experienced. Linked in certain other ways with another natural object -the human organism- they are how things are experienced as well".

So, to conclude, what is the gift that a problem might bring to us? Maybe the openness and the constraints needed to risk something else, to look for new differences. If instead of considering sts acute and constructive critique of the ways in which the individual and its psychological life have been marshalled into our knowledge and research practices as a death certificate, we consider it as a form of inventive problem-making (cf. Motamedi-Fraser, 2012) and a new set of demands for psychology, we could enrich our understanding of the individual. If we don't identify the psychological with the idealist traditions that turn experience into a "matter of "deep interiority", of inward sensibilities based on soulfulness, love, passions, genius, inspiration, suffering and authenticity" (Jackson, 1989, p. 24), if we also resist the temptations of an eliminativist form of empiricism where explanations seems to imply also a reduction of the value of that which is being explained, we might have a glimpse of a positive, even adventurous route to follow.

\section{References}

Balibar, É. (2006). My self and my own: One and the same? In B. Maurer \& G. Schwab (Eds.), Accelerating Possesion: Global Futures of Property and Personhood. New York: Columbia University Press.

Brown, S. (2010). Between the Planes: Deleuze and Social Science. In C. Jensen \& K. Rödje (Eds.), Deleuzian Intersections: Science, Technology, anthropology (pp. 101-120). New York \&

Oxford: Berghahn Books. 
Brown, S. (2001). Psychology and the Art of Living. Theory \& Psychology, 11(2), 171-192.

http://doi.org/10.1177/0959354301112002

Brown, S., \& Stenner, P. (2009). Psychology without Foundations: History, Philosophy and Psychosocial Theory. London: SAGE Publications Ltd.

Connolly, W. (2011). A World of Becoming. Durham, NC: Duke University Press.

Dewey, J. (1998). Experience and Nature. New York: Dover Publications Inc.

Duff, C. (2014). Assemblages of Health: Deleuze's Empiricism and the Ethology of Life. London: Springer.

Jackson, M. (1989). Paths Toward a Clearing: Radical Empiricism and Ethnographic Inquiry. Bloomington: John Wiley \& Sons.

James, W. (1950). The Principles of Psychology, Vol. 1. Newburyport: Dover Publications.

James, W. (1987). The Varieties of Religious Experience: A Study in Human Nature. In Writings 19021910 (pp. 1-477). New York: The Library of America.

James, W. (2009). La Voluntad de Creer. Barcelona: Marbot Ediciones.

Latour, B. (2004a). How to Talk About the Body? the Normative Dimension of Science Studies. Body \& Society, 10(2-3), 205-229. http://doi.org/10.1177/1357034X04042943

Latour, B. (2004b). Politics of nature: how to bring the sciences into democracy. Cambridge, Mass.: Harvard University Press.

Law, J. (2008). Actor-network theory and material semiotics. In B. S. Turner (Ed.), The New Blackwell Companion to Social Theory, 3rd Edition (3rd ed., pp. 141-158). Oxford: Blackwell.

Law, J., \& Mol, A. (1995). Notes on materiality and sociality. Sociological Review, (43), 274-294.

Mol, A. (2010). Actor-Network Theory: sensitive terms and enduring tensions. Kölner Zeitschrift Für Soziologie Und Sozialpsychologie, 50(1), 253-269.

Motamedi-Fraser, M. (2012). Once upon a problem. The Sociological Review, 60(S1), 84-107.

Nichterlein, M., \& Morss, J. R. (2016). Deleuze and Psychology: Philosophical Provocations to Psychological Practices. New York, NY: Routledge. 
Pols, J. (2005). Enacting Appreciations: Beyond the Patient Perspective. Health Care Analysis, 13(3), 203-221. http://doi.org/10.1007/s10728-005-6448-6

Pols, J. (2014). Knowing Patients Turning Patient Knowledge into Science. Science, Technology \& Human Values, 39(1), 73-97. http://doi.org/10.1177/0162243913504306

Puig de la Bellacasa, M. (2012). "Nothing comes without its world": thinking with care. The Sociological Review, 60(2), 197-216. http://doi.org/10.1111/j.1467-954X.2012.02070.x

Rekret, P. (2016). A critique of new materialism: ethics and ontology. Subjectivity, 9(3), 225-245. http://doi.org/10.1057/s41286-016-0001-y

Whitehead, A. N. (1995). The Concept of Nature. The Tarner Lectures Delivered in Trinity College November 1919. Cambridge, New York \& Melbourne: Cambridge University Press. 